\title{
CULTURA INDÍGENA E IDENTIDADE NACIONAL
}

\author{
INDIGENOUS CULTURE AND NATIONAL IDENTITY
}

\author{
Maria Vitória Silva PAIVA ${ }^{1}$
}

RESUMO: A ideia de uma identidade nacional foi sendo construída; não havia, inicialmente, um Brasil como hoje conhecemos. Essa noção começa a se solidificar entre os anos de 1940 a 1950. As pessoas se identificavam pelo local onde nasciam, onde sua família estava enraizada, não pela sua nacionalidade. A história do país foi e é construída por um processo contínuo de inclusão-exclusão, o que faz com que diferentes grupos sociais e identitários continuem num processo de busca pela sua afirmação, em especial os indígenas e a população afro-brasileira. A metodologia utilizada na construção deste artigo foi a pesquisa bibliográfica e a pesquisa de campo, tanto atuando como psicóloga no grupo de saúde mental que existe dentro da aldeia Jaraguá, em São Paulo, como nas visitas às aldeias Guarani de Paraty, Rio de Janeiro, e entrevistas com três indígenas, das etnias Guarani, Pitaguary e Tibiriça.

PALAVRAS-CHAVE: Identidade indígena. Terapia comunitária. Relações étnicoraciais.

ABSTRACT: The idea of a national identity was being built, there was no Brazil as we know it today. This notion began to solidify between the years 1940 and 1950. People identified where they were born, where their family was rooted, not by their nationality. The country's history was and is built through a continuous process of inclusionexclusion, which causes different social groups and identities to continue in a process of searching for their affirmation, especially the indigenous and the Afro-Brazilian population. The methodology used in the construction of this article was the bibliographical research and field research, both acting as a psychologist in the mental health group in indigenous Jaraguá village in São Paulo, as well as visits to Guarani villages in Paraty, Rio de Janeiro and interviews with three indigenous people of the Guarani, Pitaguary and Tibiriça ethnic groups.

KEYWORDS: Indigenous people. Community therapy. Ethnic and racial relations.

\section{A representação da população indígena na cultura nacional}

Um índio descerá de uma estrela colorida e brilhante De uma estrela que virá numa velocidade estonteante

${ }^{1}$ Psicóloga clínica, institucional, de família e de casal. Mestre em Relações Étnico-raciais, cursando Especialização em Dependência Química pela UNIFESP (2016-17). Terapeuta Comunitária, Consteladora Familiar Sistêmica. E-mail: vitapaiva1@ hotmail.com 
Depois de exterminada a última nação indígena E o espírito dos pássaros das fontes de água límpida Mais avançado que a mais avançada das mais avançadas das tecnologias

Virá, impávido que nem Muhammed Ali, virá que eu vi Apaixonadamente como Peri, virá que eu vi Tranqüilo e infalível como Bruce Lee, virá que eu vi $O$ axé do afoxé, filhos de Ghandi, virá

(Caetano Veloso)

A música "Um Índio", de Caetano Veloso, nos faz refletir acerca da construção de uma identidade indígena e nacional, sobre quem é o povo brasileiro. Faz alusão à noção de progresso, que pode ser perversa no que diz respeito à destruição do meio ambiente. Faz um paralelo entre figuras heróicas, como Muhammed Ali (1942-2016), pugilista norte-americano considerado um dos maiores heróis do esporte, o índio Peri, herói do romance “O Guarani” de José de Alencar (1957) e Bruce Lee (1940-1973), artista das artes marciais. Todos estes são vencedores, que, assim como a cultura indígena, num ideário triunfarão. Identificamos, assim, que a escolha dos heróis também remete a uma mistura de etnia ou grupos raciais.

Deste modo, podemos compreender que uma identidade nacional deve ser construída a partir de cada um de nós, unindo a ingestão e a digestão das diferentes culturas que contribuíram e ainda contribuem para sermos quem somos.

$\mathrm{Na}$ década de 1950, o modelo nacional que articulou raça e sociedade se tornou tema de interesse científico em vários países. No clima do pós-guerra, a UNESCO promoveu diversos estudos sobre as relações raciais no Brasil. Esse tema ganhou interesse nesse período pelo fato de pesquisadores do período de 1930 apontarem para a superficialidade da igualdade entre as raças no país. Tais investigações colocaram em questão o mito da "democracia racial”, conforme mencionam (MAIO, 1998, p. 23 apud PAIVA, 2015).

O discurso com base na discriminação étnica e racial limita e impede o convívio harmônico entre os povos, acarretando falta de oportunidade e defesa, acirra a intolerância uma vez que interdita e criminaliza aqueles que são "diferentes". Essas diferenças geram expectativas desiguais, inclusive econômicas, entre brancos, negros e indígenas no Brasil. 


\section{Terapia comunitária integrativa sistêmica e antropologia cultural}

A Terapia Comunitária é uma técnica para ser aplicada em grupos e comunidades. Foi criada pelo Psiquiatra e Professor universitário Adalberto de Paula Barreto e tem como objetivos: 1. Reforçar a dinâmica interna de cada indivíduo, para que este possa descobrir seus valores, suas potencialidades e tornar-se mais autônomo e menos dependente; 2. Reforçar a autoestima individual e coletiva; 3 . Redescobrir e reforçar a confiança em cada indivíduo, diante de sua capacidade de evoluir e de se desenvolver como pessoa; 4. Valorizar o papel da família e da rede de relações que ela estabelece com o seu meio; 5. Suscitar, em cada pessoa, família ou grupo social, sentimento de união e de identificação com seus valores culturais; 6. Favorecer o desenvolvimento comunitário, prevenindo e combatendo as situações de desintegração do indivíduo e das famílias, por meio da restauração e fortalecimento dos laços sociais; 7. Promover e valorizar as instituições e práticas culturais tradicionais que são detentoras de saber e guardiãs da identidade cultural; 8. Tornar possível a comunicação entre as diferentes formas do saber popular e saber científico (Barreto, 2008).

A Antropologia Cultural é uma das teorias estudadas na formação do Terapeuta Comunitário e dedica-se um módulo do curso para este tema. Considera-se importante que o aluno entre em contato com a sua identidade étnico-racial e cultural a partir da literatura, do resgate das memórias por meio da tradição oral, das vivências terapêuticas e das atividades culturais que fazem parte da cultura nacional e local.

Alguns exemplos de culturas populares ancestrais que permanecem vivas ao longo das gerações são o Reizado ou Folia de Reis, Maracatu, Congada, Boi-Bumbá ou Bumba-meu-boi (o nome varia dependendo da região onde é celebrada). Há também o Festival de Parintins, um Festival Folclórico que é realizado anualmente na cidade de Parintins, localizada no estado do Amazonas. No Festival, duas Associações de Boi competem entre si, o Garantido, de cor vermelha e o Caprichoso, de cor azul. Os dois bois exploram os rituais indígenas, as lendas e a cultura local. Esta é uma das festas mais populares do Amazonas.

Quero registrar uma importante contribuição sobre como é ser indígena no Brasil, feita pelos indígenas Fátima Tibiriçá e Benício, numa conversa com Dora Otaviano, do Polo formador "Afinando a Vida", ocorrida no Réveillon de 2016, na Pousada Ocas do Índio. 
Benício, da etnia Pitaguary e geógrafo, fala sobre sua experiência como colaborador do Dr. Barreto na temática da Antropologia, na formação em Terapia Comunitária. Relata que ainda existe uma ideia ultrapassada sobre o que é ser indígena e isso é demonstrado nas perguntas que os formandos lhe fazem, por exemplo: "O índio não anda pelado?", "Vocês têm celular?". Respondendo a estes questionamentos, ele fala de como esta forma de pensar está parada no tempo e questiona: "Se eu tenho que estar nu, como você deveria estar? Usando aquele monte de roupas e perucas?". Ele refere que a cultura está em constante transformação, que ela é dinâmica, embora a escola, em sua opinião, não contribua muito para essa mudança de paradigma. Para Benício, ser índio no Brasil é se reafirmar com a cultura. Ele se refere à percepção enviesada de algumas pessoas que se declaram ser negras ou indígenas para obter alguma vantagem, citando o exemplo das Políticas de Ação Afirmativa: “[...] todo mundo é índio, todo mundo é negro, minha bisavó era índia, mas na hora da retomada, da manifestação, da luta mesmo, aí eles pulam fora” Resume: “[...] ser índio é você afirmar sua identidade, seguir as tradições das pinturas, dos rituais de espiritualidade, do Ouricuri, então, é isso que é ser índio, é saber de onde veio para saber para onde vai”.

Para Fátima, ser índio é estar em constante luta pela terra. Ela cita os amigos Tapebas da região de Caucaia, cidade situada na região metropolitana de Fortaleza; eles estão lutando contra um latifundiário que afirma ser dono das terras indígenas. Essa situação ocorre também com os quilombolas. Infelizmente, no Brasil, a tradição é de desrespeito ao direito à terra de quem nela produz e com ela tem estreito vínculo. Fátima relata que não precisa ser índio para lutar pela causa indígena, basta ser humano, e finaliza dizendo que o índio sem terra é como a aranha sem a teia, pois, é a teia que nutre a aranha, que lhe permite se deslocar, trabalhar e viver. Destruí-la é eliminar suas possibilidades de autonomia e de vida. A aranha sem a teia é como o índio sem a terra, uma comunidade sem a solidariedade (Barreto, 2009, p. 46). Ainda hoje, considerando a formação étnica do povo brasileiro, observa-se um resquício do processo de colonização, a considerar a forma como as elites e as religiões hegemônicas tratam as culturas que não são de origem europeia. Barreto (2009) nos chama a atenção para a sua experiência na formação religiosa na Igreja Católica, de como estas questões o interpelavam. Ele via contradição entre o discurso e a prática, visto que o objetivo era formar pessoas que fossem capazes de lutar contra a opressão e as injustiças: “Ao mesmo tempo em que nos educam para uma boa causa, nos educam também contra os valores da educação de nossas famílias, contra nossas origens" (p. 46). 
Esses discursos reforçam a inferioridade de algumas etnias ou culturas e estão carregados de sentido ao utilizarem termos como "selvagens" e "tribo de índios". Eles têm o propósito de ou colocar o outro no seu lugar ou mostrar que ou se é índio, por exemplo, ou se é religioso, ou cientista, e ambos não devem conviver juntos. A Antropologia Cultural na Terapia Comunitária contribui muito para desconstruir essas ideias fixas, pois consideramos que quanto mais inundado de suas origens, de sua cultura, pertencendo ao seu grupo, mais o sujeito se individualiza e se empodera.

Se a cultura for vista como um valor, um recurso que deve ser reconhecido, valorizado, mobilizado e articulado de forma complementar com os outros conhecimentos, poderemos ver que este recurso nos permitirá somar, multiplicar nossos potenciais de crescimento e de resolução de nossos problemas sociais e construir uma sociedade mais fraterna e mais justa. (Barreto, 2008, p. 29)

\section{Sobre letramento(s) das relações étnico-raciais}

O uso do conceito de "letramento" se deu na academia com o objetivo de separar os estudos sobre o impacto social da escrita dos estudos sobre a alfabetização, visto que este último destaca as competências individuais no uso e na prática da escrita. Deste modo, discute-se a melhor utilização da terminologia "letramento" em lugar de "alfabetização", considerando que este conceito é mais abrangente, levando ao desenvolvimento da consciência crítica, flexibilização da cultura e um processo de libertação.

A palavra "letramento" não é ainda dicionarizada. Pela complexidade e variação dos tipos de estudos que se enquadram nesse domínio, podemos perceber a complexidade do conceito. Assim, se um trabalho sobre letramento examina a capacidade de refletir sobre a própria linguagem de sujeitos alfabetizados versus sujeitos analfabetos (por exemplo, falar de palavras, sílabas e assim sucessivamente), então, segue-se que para esse pesquisador ser letrado significa ter desenvolvido e usar uma capacidade metalinguística em relação à própria linguagem. (KLEIMAN, 1995 apud PAIVA, 2015).

Pelo seu caráter social e cultural, letramento tem caráter transformador. Segundo Soares (2000, p. 37.), com o letramento, uma pessoa "[...] muda seu lugar social, seu modo de viver na sociedade, sua inserção na cultura e sua relação com os outros, com o contexto, com os bens culturais, torna-se diferente" (p. 186). 
Podemos compreender letramento(s) de um modo plural ou como "[...] um conjunto de práticas sociais, cujos modelos específicos de funcionamento têm implicações importantes para as formas pelas quais os sujeitos envolvidos nessas práticas constroem relações de identidade e de poder" (KLEIMAN, 1995, p.11).

Segundo Hall (2000), podemos pensar na identidade como não integral, originária e unificada. A ideia de sistemas circulantes no sentido de mudanças constantes que considera as complexidades, as recursividades e as contradições. Importa ampliar o foco da observação, contextualizar o fenômeno. $\mathrm{O}$ autor fala da necessidade de olhar a identidade de forma discursiva, desconstruída, não focar no paradigma que foi criado.

Assim, é necessário considerar a sociodiversidade presente na sociedade brasileira, que é formada de povos e culturas diferentes; no entanto, há culturas hegemônicas, enquanto as demais estão num processo contínuo de afirmação e solidificação. Como o processo histórico é contínuo, a sociedade vai se construindo num processo de desconstrução. Os questionamentos devem permear nossa existência, conforme nos aponta Silva (2012, p.39):

Por que atualmente são obrigatórias rampas em prédios públicos, destinadas às pessoas portadoras de deficiência? Porque existe Delegacia para as mulheres? O porquê do Estatuto do Idoso? Qual a razão do Estatuto da Criança e do Adolescente-ECA? O porquê da Lei 11.645-2008, que tornou obrigatória a inclusão nos currículos escolares o ensino da História e Cultura afro-brasileiras e indígenas?

A resposta a esses questionamentos nos aponta para uma nova configuração da sociedade brasileira, na qual as minorias estão se organizando para reivindicar a participação de modo mais equilibrado na vida social, no trabalho e na política do país. Ou seja, esse processo é o resultado de décadas de lutas sociais dos povos indígenas e afro-brasileiros, que cobram da elite política e econômica Políticas Públicas de Ação Afirmativa como forma de reparação e inclusão. Para Ribeiro (2014, p. 254), as ações afirmativas devem ser vistas como um conjunto de mecanismos que favorece o acesso econômico e político de grupos que historicamente foram discriminados: "Nesse sentido, faz-se importante compreender a fundamentação desse intenso debate sobre as ações afirmativas, que delineia os posicionamentos favoráveis e contrários à sua importância e pertinência”.

A lei n. 11. 645, de março de 2008: 
Art. 26-A. Nos estabelecimentos de ensino fundamental e de ensino médio, públicos e privados, torna-se obrigatório o estudo da história e cultura afro-brasileira e indígena.

$\S 1^{\circ} \mathrm{O}$ conteúdo programático a que se refere este artigo incluirá diversos aspectos da história e da cultura que caracterizam a formação da população brasileira, a partir desses dois grupos étnicos, tais como o estudo da história da África e dos africanos, a luta dos negros e dos povos indígenas no Brasil, a cultura negra e indígena brasileira e o negro e o índio na formação da sociedade nacional, resgatando as suas contribuições nas áreas social, econômica e política, pertinentes à história do Brasil.

Embora essa lei tenha sido promulgada há oito anos, o que conhecemos e ouvimos são relatos de dirigentes e professores que não a colocam em prática, com a justificativa de não estarem preparados para tal; estes utilizam a religião como forma de descumprir a lei e infringem a constituição duplamente: quando não a cumprem e quando fazem uso da religião num estado laico. A importância de estudar e promover as culturas, especialmente as minoritárias, contribui com o desenvolvimento cultural e possibilita o convívio harmonioso e o desenvolvimento econômico em condições mais igualitárias.

De acordo com Barreto (2008), “[...] na Terapia Comunitária, a cura passa pelo resgate das raízes e dos valores culturais que despertam no homem o valor e o sentido da pertença” (p.235), assim, o equilíbrio físico e mental se dá a partir da integração do indivíduo com a sua origem, favorecendo a superação dos sofrimentos.

\section{População indígena no Brasil}

De acordo com o Censo Demográfico de 2010 do IBGE - Instituto Brasileiro de Geografia e Estatísticas, o Brasil era composto de 190.755.799 milhões de pessoas, e a população indígena no território nacional, composta de 817.963 mil pessoas, dos quais 502.783 vivem na zona rural e 315.180 habitam as zonas urbanas brasileiras. Este censo revelou que em todos os estados da federação, inclusive no Distrito Federal, há populações indígenas. A FUNAI também registra 69 referências de índios ainda não contatados, além de existirem grupos que estão requerendo o reconhecimento de sua condição indígena junto ao órgão federal indigenista. Comparando com a população brasileira em geral, há um destaque no percentual da população indígena vivendo no campo: $63,8 \%$, contra $15,6 \%$ da população em geral, ao passo que apenas $36,2 \%$ dos 
indígenas, em contraste com $84,4 \%$ da população em geral, vive nos centros urbanos. Esses dados revelam um estreito vínculo dos indígenas com terra e os possíveis prejuízos vivendo fora dela na manutenção dos seus hábitos alimentares e culturais.

A comunidade indígena passa por uma rápida e complexa transformação social. Desse modo, necessita buscar novas respostas para a sua sobrevivência física e cultural e garantir às próximas gerações melhor qualidade de vida. Os diferentes grupos vêm enfrentando problemas concretos, como invasões e degradações territoriais e ambientais, exploração sexual, aliciamento e uso de drogas, exploração de trabalho, inclusive infantil, mendicância, êxodo desordenado, causando grande concentração de indígenas nas cidades em condições de miséria. Ainda segundo o Censo do IBGE, esses 817.963 indígenas são formados por 305 diferentes etnias. No que se refere às línguas faladas, elas são 274; o Censo também demonstrou que cerca de 17,5\% da população indígena não fala a língua portuguesa.

Desde 1500 até a década de 1970, a população indígena brasileira decresceu acentuadamente, e muitos povos foram extintos. O desaparecimento dos povos indígenas passou a ser visto como uma contingência histórica, algo a ser lamentado, mas pouco combatido. No entanto, este quadro começou a dar sinais de mudança nas últimas décadas do século passado. A partir de 1991, o IBGE incluiu os indígenas no Censo demográfico nacional. O contingente de brasileiros que se considera indígena cresceu $150 \%$ na década de 1990 . O ritmo de crescimento foi quase seis vezes maior que o da população em geral. O percentual de indígenas em relação à população total brasileira saltou de 0,2\% em 1991 para 0,4\% em 2000, totalizando 734 mil pessoas. Houve um aumento anual de $10,8 \%$ da população, a maior taxa de crescimento dentre todas as categorias, quando a média total de crescimento foi de 1,6\%. Entretanto, devese considerar que as mudanças introduzidas na metodologia de pesquisa adotada pela instituição no Censo de 2010 e utilizada pelos recenseadores contribuiu para o aumento das pessoas que se declararam como indígena.

Foi introduzido um conjunto de perguntas específicas para as pessoas que se declararam indígenas, como o povo ou etnia a que pertenciam, como também as línguas indígenas faladas. Além disso, incorporou-se um novo recorte geográfico, que foi a localização do domicílio indígena - dentro ou fora de Terras Indígenas já reconhecidas pelo governo federal. (FUNAI, 2017). 
Figura 1: Gráfico População Indígena no Brasil

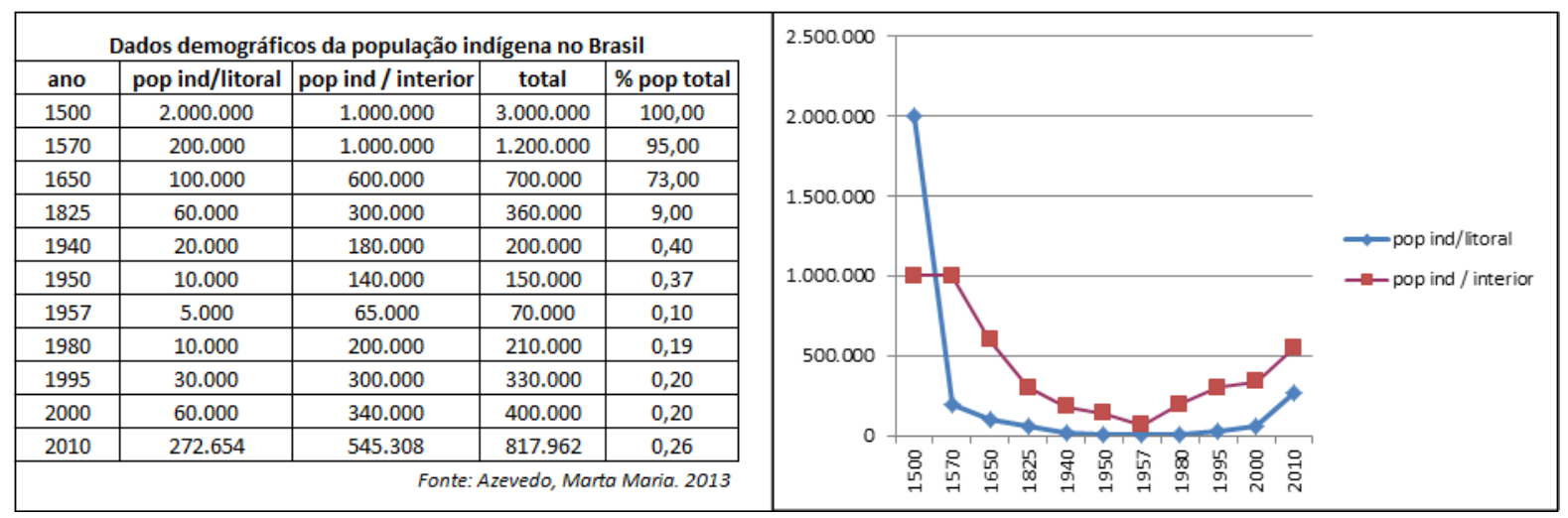

Fonte: IBGE, 2010.

Figura 2: Gráfico Distribuição População Indígena nas Regiões Brasileiras

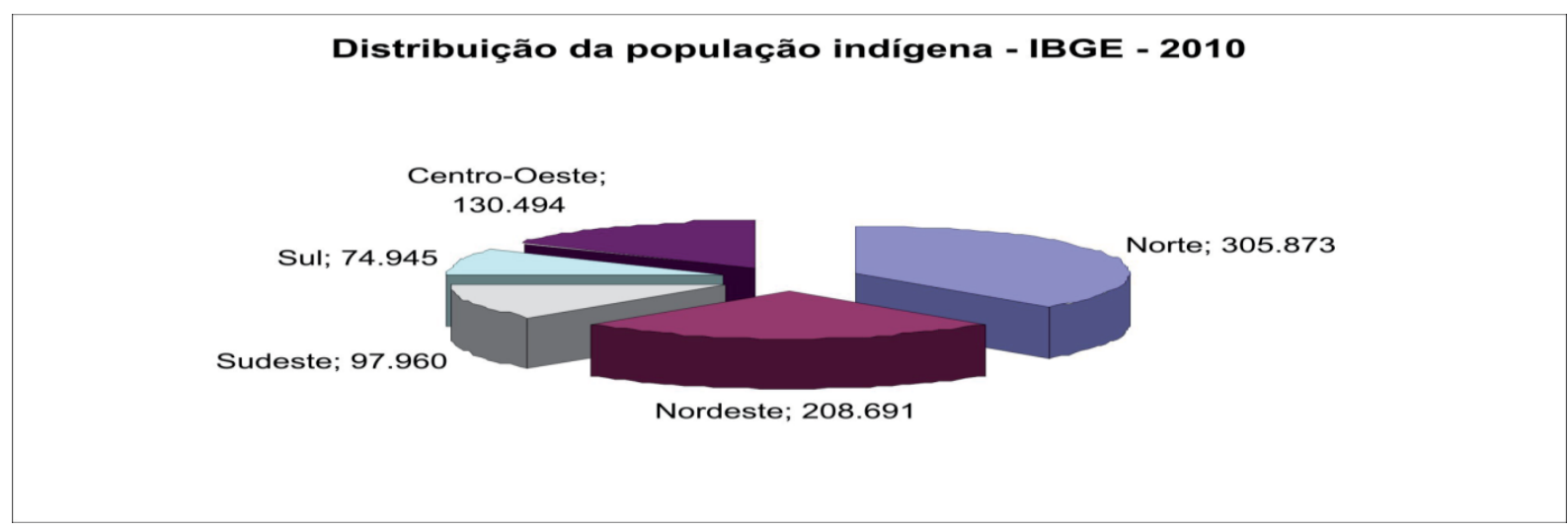

Fonte: IBGE, 2010.

\section{Aldeia urbana em São Paulo}

Durante aproximadamente quatro meses do primeiro semestre do ano de 2016 tivemos uma experiência muito positiva, integrando o grupo de saúde mental da Aldeia indígena que está localizada dentro da cidade de São Paulo, no bairro do Jaraguá, limite com o município de Osasco, região noroeste, onde está a Terra Indígena Jaraguá. A aldeia é habitada por indígenas da etnia Guarani, historicamente formada tanto por grupos falantes do dialeto Mbya como do dialeto Nhndeva (ou Xiripa). A necessidade 
da criação do grupo se deu, entre outras questões, devido ao alto índice de indígenas que faz uso abusivo de álcool e outras substâncias psicoativas, trazendo grandes prejuízos tanto pessoais como para as famílias e a comunidade em geral.

Sobre a Terra Guarani Jaraguá, documentos do extinto SPI apontam seu povoamento no ano de 1950, com a chegada do líder André Samuel dos Santos, que fugira da Terra Indígena em Itanhaém após ser detido, segundo documentos do SPI, para corrigir seus "maus costumes", que nada mais eram do que suas práticas tradicionais. Lá ele se estabeleceu com sua família, da qual ainda hoje restam alguns descendentes. De acordo com a Constituição Federal de 1988, Lei 6001/73 e do Estatuto do Índio, Decreto $\mathrm{n}^{\circ} 1775 / 96$, as terras indígenas são classificadas nas seguintes modalidades: Terras Indígenas Tradicionalmente Ocupadas, Reservas Indígenas, Terras Dominiais e Interditadas. O território pertencente à aldeia é de 1,7566 hectares (terra regularizada e tradicionalmente ocupada) e 532,0000 hectares (terra declarada e tradicionalmente ocupada), conforme os dados da FUNAI. Terras declaradas, de acordo com a FUNAI, são terras que obtiveram a expedição da Portaria Declaratória pelo Ministério da Justiça e estão autorizadas para serem demarcadas fisicamente, com a materialização dos marcos e georreferenciamento. Há décadas aquela comunidade luta pela regularização do território de onde foram expulsos desde a construção da Rodovia dos Bandeirantes, no ano de 1970, e depois, com a construção do Rodoanel Mario Covas, que resultou na fragmentação do seu território e na urbanização da região.

Levando em conta as características do povo indígena, que vive em áreas territoriais extensas, com uma baixa densidade populacional, e considerando o estreito vínculo do indígena com a terra, podemos considerar o prejuízo para essa população viver num território tão restrito. Atualmente, sem terra para cultivar, praticamente a única fonte de renda da população que vive naquele local é proveniente de Programas de Transferência de Renda, conforme informações de funcionários da Unidade Básica de Saúde da Aldeia. De acordo com os mesmos, apenas uma meia dúzia de indígenas tem algum trabalho formal e essa atividade é exercida dentro da própria comunidade. Assim, observa-se uma mudança no estilo de vida dos indígenas, que pensa o trabalho de outro modo: eles trabalham cultivando a terra, pescando, fabricando seus instrumentos de trabalho e fazendo artesanato, diferente do modo de trabalho do Jurua, terminologia para classificar os não-indígenas ou europeu.

Outra consequência para a população indígena que está em contato direto com não-indígenas, visto que a aldeia está dentro do perímetro urbano, é a adoção de hábitos 
alheios à sua cultura; um exemplo disso é o abuso de álcool e outras drogas, além de outras vulnerabilidades, como relataram os moradores no grupo de saúde mental. É possível identificar uma população indígena vivendo nas ruas nos arredores da aldeia, em consequência dos prejuízos provocados pela dependência das drogas.

Figura 3: Sala de Aula de Aldeia

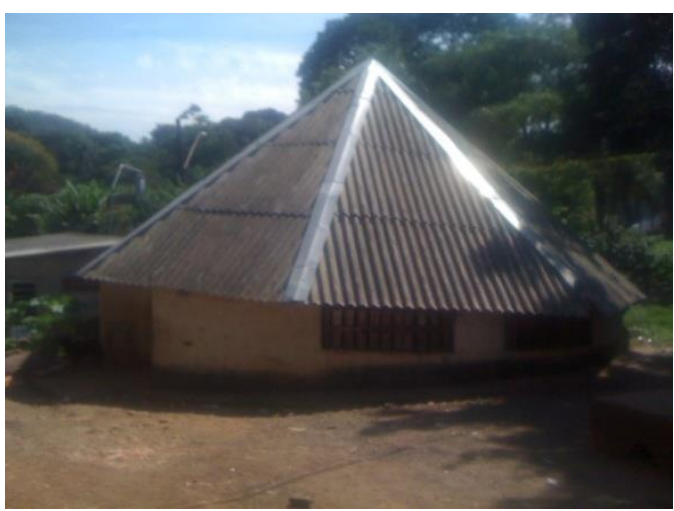

Fonte: Arquivo pessoal

Figura 4: Casa de Aldeia

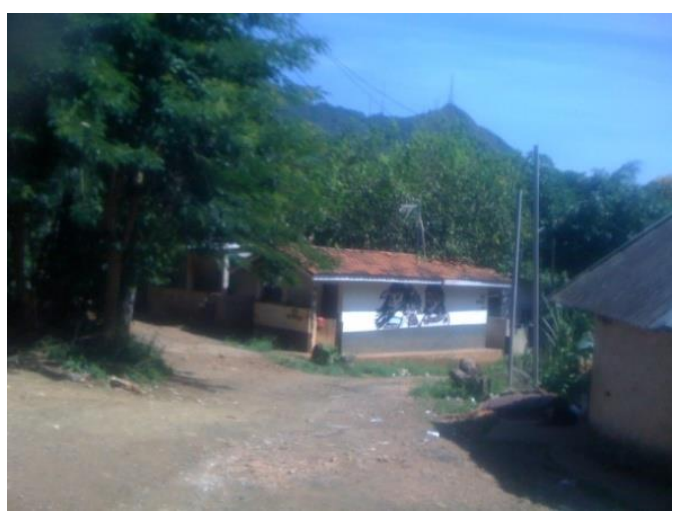

Fonte: Arquivo pessoal

Visita à aldeia Guarani de Paraty - Rio de Janeiro

Numa visita à Aldeia Guarani de Paraty, no estado do Rio de Janeiro, no mês de março de 2016, foi possível ver e ouvir a história e a cultura de um povo narrada por umas das líderes da comunidade, a Sra. Ivanilda: 
"A gente anda muito, mas a gente anda não por andar, a gente anda à procura da terra sem mal. Para nós, o Paraguai é o centro da Terra. Há muitos anos atrás o Paraguai era o centro onde os guaranis viviam e saíram para procurarem a terra sem mal, que seria depois do oceano. A terra sem mal é uma terra que tem fartura, uma terra que não tem doença, que não tem morte. Isso é o que os mais velhos acreditam, eu mesma acredito nisso ainda, acredito nessa história do nosso caminhar milenar".

De acordo com o antropólogo Darcy Ribeiro (2000), falando sobre o sincretismo cultural e religioso do país: o "Brasil nasce sobre o signo da utopia, a terra sem males, a morada de Deus". Para o autor, a humanidade indígena é uma humanidade diferente, trata-se de um povo que agradece a Deus pela beleza do mundo. Para os indígenas a vida é feita para viver, essa é a sua finalidade.

\footnotetext{
"Apesar de termos roupa, calçado, alguns têm celular, meu marido tem um carro, mas isso não quer dizer nada para a gente, isso é como se fosse um brinquedo. Nossa maior importância é a nossa história, nossa valorização, de nada adianta você ser índio e não valorizar a sua cultura. Para a gente o mais importante é a nossa valorização, dai é que sustenta a nossa sabedoria, nossa força, de saber o que você é. Tudo na nossa história, o importante é valorizar. As crianças crescem fortes na cultura e assim não irão se perder". (narrativa de Ivanilda)
}

Ainda conforme Ribeiro (2000), na força da sua cultura um indígena basta a si mesmo, ele é autossuficiente. Ele sabe produzir tudo que necessita ao longo da sua vida: caça, planta, fabrica seus próprios instrumentos de trabalho, artesanato, identifica as espécies de alimentos ou medicamentos. O menino indígena é formado para ser um caçador, um guerreiro, e a menina para ser uma tecelã, uma mulher trabalhadora. $\mathrm{Na}$ cultura indígena, segundo Ribeiro, tudo deve ser perfeito, pois tudo os retrata, ou seja, uma vontade de beleza. Na cultura não existe uma distinção clara entre trabalho e arte. O ideal de homem e mulher dentro da cultura leva em conta se a pessoa está de acordo com essa tradição. 
Figura 4: Comunidade Guarani de Paraty - RJ

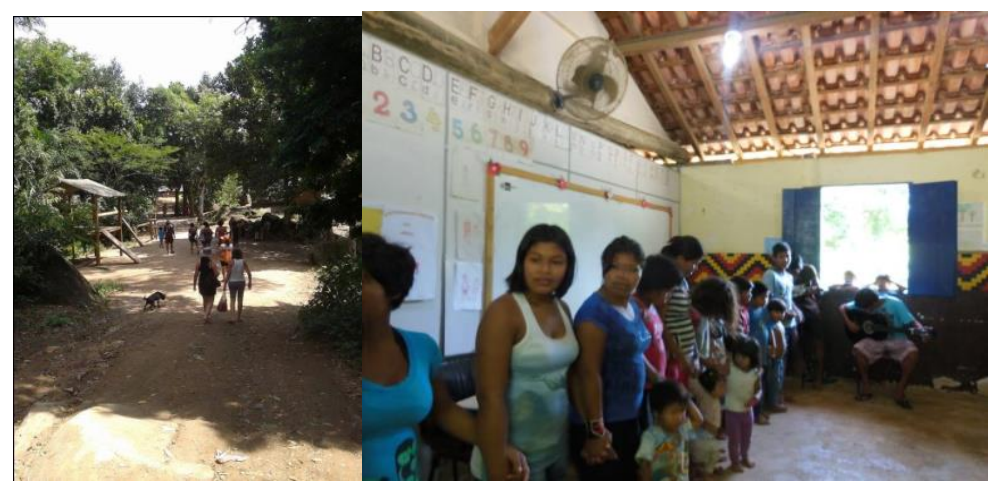

Fonte: Arquivo pessoal

Existe uma variedade enorme de ritmos e danças na cultura indígena, variando de tribo para tribo. No estado do Pará, por exemplo, o nome Carimbó foi dado pelos indígenas aos dois tambores de dimensões diferentes que servem para o acompanhamento básico do ritmo. Carimbó - Curi (Pau) e Mbó (Oco ou furado), significa pau que produz som. Em alguns lugares do interior do Pará prevalece o título original de "Dança do Curimbó".

Em muitas sociedades indígenas a música tem grande importância na representação de ritmos e mitos. Os tipos de instrumentos variam de acordo com a tribo e eles são utilizados de formas diferentes. Um exemplo desses instrumentos é o maracá ou chocalho. Em algumas tribos esse instrumento é utilizado em rituais religiosos e em outras para marcar o ritmo dos cânticos, por exemplo. A dança para os indígenas é diferente do nosso jeito de dançar, eles não dançam em par, isso é raro; normalmente, se dá uma dança de apenas um indivíduo ou do grupo.

\section{Considerações Finais}

Com o resultado da nossa pesquisa, observa-se um Brasil plural, sem uma identidade nacional única; o que vimos são "Brasis", terminologia muito utilizada por Darcy Ribeiro. A luta do povo indígena continua sendo no sentido de exigir respeito à sua identidade e ao seu estilo de vida, que possui um vínculo direto e harmonioso com a natureza.

A beleza da sua cultura é revelada na sua arte: música, dança, artesanato, 
religião, comida, na língua falada por cada povo e no viver em harmonia com a natureza, no tipo de moradia que é mais coletiva; mas, para isso, seus territórios precisam ser preservados da ganância daqueles que têm como único interesse acumular riquezas, sem se importar com a apropriação dos bens alheios e coletivos. A usurpação das propriedades, infelizmente, tem sido uma prática cada vez mais corrente na nossa sociedade, e vem sendo manifestada de modo cada vez mais contundente no meio político do nosso país.

Os rituais e a hierarquia fazem parte da cultura indígena. O pajé é o líder religioso, ele é o chefe e o representante da tradição: "Se o fillho se cria na etnia dos pais, na língua dos pais, ele continua sendo ele mesmo, a convicção é o que faz dos índios, índios" (Ribeiro, 2000). Esse fragmento nos remete à fala da líder da aldeia de Paraty, a Sra. Ivanilda, de Fátima Tibiriça e Benício, os dois últimos do Ceará.

Os hábitos alimentares variam de acordo com a região onde está localizada a tribo; por exemplo, os indígenas que vivem nas regiões amazônicas têm o açaí como um ingrediente típico da sua alimentação. Porém, esses costumes mudam de acordo com os produtos fornecidos pela natureza, conforme a localização das comunidades.

Essa cultura milenar não pode ficar desconhecida do resto da população; nesse sentido, a lei n. 11.645 presta um grande serviço à nação, que enriquece quando conhece a sua origem e valoriza a cultura do seu povo, a diversidade pela qual é formada; só falta a mesma ser colocada em prática, e para isso precisamos cobrar sua efetivação.

Deste modo, a Terapia Comunitária Sistêmica Integrativa é uma metodologia de trabalho indicada para ser desenvolvida nas comunidades indígenas, pois pode contribuir com o fortalecimento da cultura e ajudar a melhorar a organização e a fortalecer a comunidade enquanto grupo, impulsionando-a a lutar pelos seus direitos e a superar os problemas internos, tais como o uso abusivo de álcool e outras drogas, conforme mencionado anteriormente, e os problemas externos, que também não são poucos. Inclusive, não podemos esquecer que alguns indígenas fizeram a formação com o Professor Adalberto para realizar a prática em suas comunidades. 
Agradecimentos: Sou grata, em primeiro lugar, aos meus ancestrais que me deram a vida e à vida pelas oportunidades de experimentar tantas coisas boas, como as amizades, o prazer do contato com as belezas da natureza, aprender, evoluir e amar. Agradeço a Salete Viana do CEAF, cujo amor pela Terapia Comunitária mobiliza as pessoas, agradeço pelos ensinamentos e pelo carinho. Sou grata à amiga e parceira Mari Teixeira do NAC de Araraquara pelas oportunidades e aprendizados. Agradeço a Malu e a Greice do CAIFICOM pela partilha e pelo carinho. Gratidão às minhas amigas e companheiras do Afinando a Vida, Dora, Neusa e Nadja. Gratidão aos formandos, com os quais o tempo todo eu aprendo o valor da troca, pois já sabemos que é dando que se recebe e que águas paradas não movem moinhos.

\section{REFERÊNCIAS}

BARRETO, A. de P.; BOYER, Jean-Pierre. O índio que vive em mim: o itinerário de um psiquiatra brasileiro. São Paulo: Terceira Margem, 2009.

BARRETO, Ad. de P. Terapia Comunitária passo a passo. Fortaleza: Gráfica LCR, 2008 .

GUIMARÃES, A. S. A. Preconceito racial: modos, temas e tempos. São Paulo: Cortez, 2008.

GUIMARÃES, A. S. A. Racismo Anti-Racismo no Brasil. São Paulo: Editora 34, 2005.

HALL, S. Identidade e diferença: a perspectiva dos estudos culturais. Petrópolis: Vozes, 2000.

KLEIMAN. A. B. (org). Os significados do letramento: uma nova perspectiva sobre a prática social da escrita. Campinas, SP: Mercado de Letras, 1995.

PAIVA, M. V. S. Se é negro é suspeito, se é suspeito é negro: uma análise discursiva da produção de suspeita em notícias da Folha de S. Paulo: 2015, f. 120, dissertação, CEFET-RJ, Rio de Janeiro, 20 de março de 2015.

RIBEIRO, D. Documentário “O povo brasileiro”. Fundação Darcy Ribeiro, TV Cultura e GNT, 2000.

SANTOS, C. J. Crimes de preconceito e de discriminação. São Paulo: Saraiva, 2010.

SEMEGHINI-SIQUEIRA, I.; RODRIGUES, L de A. D. (orgs); dos Santos, Catarina Delfina [et al] (Elaboração). Vocabulário bilíngue: Guarani-Português/PortuguêsGuarani; aldeias do Estado de São Paulo. São Paulo: SEE, FEUSP, 2010.

SILVA, E. Povos indígenas: história, cultura e o ensino a partir da Lei 11.645. Revista historien. UFPE/Petrolina, v. 7, p, 39-49, 2012. 


\section{Como referenciar este artigo}

PAIVA, Maria Vitória Silva. Cultura indígena e identidade nacional. Revista Temas em Educação e Saúde, Araraquara, v.12, n.2, p. 230-245, jul-dez/2016. ISSN: 15177947.

Submetido em: 30/10/2016

Aprovado em: 25/11/2016 